\section{B A Institute of \\ YK Business Administration \\ 六下 \\ Karachi \\ Leadership and Ideas for Tomorrow}

\section{Business Review}

Volume 14 Issue 2 July-December 2019

7-1-2019

\title{
Estimating proportion of noise traders and asset prices
}

Mirza Faizan Ahmed

NED University of Engineering and Technology, Karachi, Pakistan

Follow this and additional works at: https://ir.iba.edu.pk/businessreview

Part of the Finance Commons

(c) (i)

This work is licensed under a Creative Commons Attribution 4.0 International License.

\section{Recommended Citation}

Ahmed, M. F. (2019). Estimating proportion of noise traders and asset prices. Business Review, 14(2), 1-12. Retrieved from https://doi.org/10.54784/1990-6587.1014

This article is brought to you by iRepository for open access under the Creative Commons Attribution 4.0 License and is available at https://ir.iba.edu.pk/businessreview/vol14/iss2/1. For more information, please contact irepository@iba.edu.pk. 


\title{
Estimating proportion of noise traders and asset prices
}

\author{
Mirza Faizan Ahmed
}

\begin{abstract}
This paper provides empirical evidence of the presence, proportion and trading behavior of noise traders in the U.S. equity market (S\&P500 index). A simple methodology is used to estimate the heterogeneous agent asset pricing model involving noise traders' risk, through GMM. Departing from previous estimations of heterogeneous agent models, it estimates fundamental price using the consumption-based asset pricing model and noise traders' misperception as deviation from this price. It concludes that noise traders exist in the S\&P500, they exaggerate price expectations as compared to fundamental traders, and traders (or investors) are rational, on average.
\end{abstract}

Keywords Asset pricing - Heterogeneous beliefs · Noise traders - Representative agent model.

\section{Introduction}

Originating from the expected utility hypothesis of Von Neumann and Morgenstern (1953) and the mean-variance framework of Markowitz (1952) several standard asset pricing models have been developed, that assume the rationality of investors, such as capital asset pricing model (CAPM), arbitrage pricing theory (APT), three-factor and five-factor models by incorporating the factors which affect asset prices such as size, value, investment, and profitability. Besides, Lucas Jr (1978) develops a purely representative agent model (RAM) of asset pricing, which also assumes rationality of economic agents. Grossman and Stiglitz (1980) and Milgrom and Stokey (1982) highlight that perfect information, which is a tenet of rationality, would simply result in no trading in the market. This strong assumption of rationality in the standard asset pricing model has created room for the emergence of behavioral asset pricing models.

Tversky and Kahneman (1974) and Tversky and Kahneman (1979) criticize the expected utility theory and develop an alternative, prospect theory. They

Mirza Faizan Ahmed

NED University of Engineering and Technology, Karachi-Pakistan

E-mail: mirzafaizan@neduet.edu.pk 
argue that the decision-making behavior of agents does not always fully comply with the assumptions of expected utility theory and they can be biased. In this perspective, behavioral finance urges that if we know how investors behave, we can understand why do prices move? The behavioral finance models are mostly heterogeneous agent models (HAMs) based on the assumption of bounded rationality or irrationality of investors. The emergence of HAMs and classification of investors originates because of market anomalies, observed investor behavior, market patterns, and alternative explanation of price movement in various studies. Under uncertainty investors do not optimize but satisfice reflecting limited cognitive capabilities for acquiring and evaluating relevant information. Here the investors do not fully comply with the assumptions of rationality and hence the best choice cannot be guaranteed (Simon 1997). The boundedly rational traders believe that a subset of information is relevant for decision making (Thaler and Shefrin 1981; Russell and Thaler 1985; De Long et al 1990b; Hong and Stein 1999; Barberis et al 2015). Most of the earlier models were theoretical or simulation based, due to non-linearity and complexity in estimation (Zeeman 1974; Kyle 1985; De Long et al 1990a,b; Barberis et al 1998).

Among several possible sources of heterogeneity like heuristics and biases, asymmetric information etc., Black (1986) conceives noise as one of the important sources. It regards noise as contrasting to information and argues that irrational traders trade because they like to trade or perceive the noise as information. Aiming to incorporate this irrational behavior, De Long et al (1990a) introduced an asset pricing model in mean-variance framework with two types of traders, rational arbitragers and noise traders. Assuming the deviation of noise traders' expectations from the fundamental value of the asset, this model concludes that rational investors limit their willingness to take positions against noise traders misperception keeping that it may persist in the future. This uncertainty in noise traders' beliefs creates a risk in the market and affects asset prices. This risk is known as noise traders' risk. Rational arbitragers, hence, require additional risk premium to get themselves compensated against this additional risk, they are exposed to. This claim requires empirical evidence about the presence of noise traders, their proportion in the market and their trading behavior.

Explanation of asset prices significantly improve by incorporating heterogeneity of beliefs in the model (Anderson et al 2005). Previous empirical studies, specifically on S\&P500, with fundamentalists and chartists provide evidences in favor of heterogeneous behavior. Fundamentalists make expectations on fundamental analysis while chartists derive the same from charts and technical analysis. Boswijk et al (2007) assumes that fundamental value is publicly known but agents have different beliefs about the deviation of price from the value. They choose and switch between mean-reversion regime or trend following regime, keeping their past performance in view. In most of the period, from 1871 to 2003, mean-reversion regime was active except for late 1990s when trend-following regime was dominant and led the prices away from fundamental value. Chiarella et al (2014) identifies the presence of chartists, in S\&P500, taking their trading decisions only on the basis of previous price change. Fundamentalists expect mean reversion in price while technical analysts or chartists destabilize it por- 
traying geometric decay process. Another similar type of model concludes that the presence of the two types of traders increase the model's explanatory power in boom and bust periods (Hommes et al 2017).

Chiarella et al (2012) concludes that along with the fundamentals and chartists, noise traders as liquidity providers, are also present in the S\&P500. Similarly, Lof (2014) draws analogous conclusion in favor of the presence of rational and contrarian speculators along with fundamentalists. Lof (2014) assumes that rational speculators buy stocks with an aim to take one period return and contrarians derive opposite expectations about return than that of the rational speculators. During 1990s, the share of contrarians was higher due to overvalued stocks suggested by VAR (Vector Autoregressive) based prediction. Contrarians were making expectations against rational speculators expecting the price to retrace back towards fundamental value in the next period. Other than these, several other HAMs for equity markets as well as forex, commodities, housing, credit, and others have also been estimated (Ter Ellen and Verschoor 2018).

These studies conclude that there exist traders bearing heterogeneous beliefs including noise traders. Modeling these types of traders along with the rational traders may help improve the explanatory power of asset pricing models as compared to the standard finance models. It is important to consider that all the above cited HAMs for S\&P500 derive fundamental value from Gordon Growth Model or Dividend Discount Model. The Gordon Growth Model is, typically, not a representative agent model but it satisfies the definition of asset pricing model as given by Cochrane (2009) with its strong assumption of constant dividend growth and discount factor. Nevertheless, consumption based asset pricing model is the basic standard representative agent model (Cochrane 2009). Hence, any argument, in favor of heterogeneous agent model, should bear the estimation of fundamental value from standard representative agent model.

This paper seeks empirical evidence of the presence of noise traders, proportion and behavior of noise trading in the S\&P500 using the asset pricing model as developed by De Long et al (1990a). Unlike previously estimated HAMs, it uses fundamental value derived from the standard consumption-based asset pricing model as estimated by Hansen and Singleton (1982). Therefore, this paper contributes in favor of the presence and behavior of the noise traders by introducing a simple methodology to estimate HAMs based on the fundamental value estimated through the standard representative agent model.

Rest of the paper is sequenced as follows. Section 2 compares the two selected models including standard representative agent (RAM) consumption based asset pricing model and De Long et al (1990a) model (HAM) with noise traders' risk in the asset pricing context. This is followed by the methodology in section 3 , estimation results in section 4 , and conclusion in section 5 .

\section{Comparison of the asset pricing models}

Asset pricing encompasses two components, expected cash flows and stochastic discount factor. The stochastic discount factor (SDF) is critical to determine the expected price or expected return by taking various risk factors into account. 
M. Ahmed

Cochrane (2009) prescribes the asset pricing equation as follows:

$$
p_{t}=E_{t}\left(m_{t+1} x_{t+1}\right)
$$

where $p_{t}$ shows asset price at time $t, m_{t+1}$ reflects stochastic discount factor at time $t+1, x_{t+1}$ indicates future cash flow on asset at time $t+1$, and $E_{t}$ expresses expectation taken at time $t$. To make the analysis simple we can write future cash flows in terms of gross return or payoff, like

$$
x_{t+1} / p_{t}=R_{t+1}=\left(1+r_{t+1}\right)
$$

where $R_{t+1}$ is asset's payoff and $r_{t+1}$ is return on asset. This relationship converts equation (1), as follows:

$$
1=E_{t}\left(m_{t+1} R_{t+1}\right)
$$

Equation (3) implies

$$
E_{t}\left(m_{t+1} R_{t+1}\right)-1=0
$$

where $m_{t+1}$, the stochastic discount factor (SDF) includes relevant risk factors that can affect asset's price. Equation (3) defines the arbitrage-free asset pricing. Standard finance argues that all securities must obey the arbitrage-free asset pricing or law of one price. In any other case, arbitragers exploit the opportunity and correct the price to its fundamental value. Hansen and Singleton (1982) estimate the consumption-based asset pricing model with GMM. The model is developed with the constant relative risk aversion (CRRA) utility function as given below:

$$
U\left(C_{t}\right)=\left(C_{t}^{\gamma}\right) / \gamma
$$

where $\gamma<1$. Maximizing the aggregate discounted expected utility subject to the expected payoff, current consumption and return using the utility function in equation (5) gives the following consumption-based asset pricing model:

$$
f\left(x_{t+1}, b_{0}\right)=\beta * R_{t+1} *\left(C_{t+1} / C_{t}\right)^{\alpha}-1=0
$$

where $b_{0}$ shows set of parameters including $\alpha$ and $\beta$. $\beta$ represents discount factor and $\alpha=\gamma-1$, hence it holds negative value for risk averse behavior. $x_{t+1}$ shows the information set (data available). $r_{t+1}$ is the real value-weighted or equal-weighted payoff during period $t+1$ on selected portfolio and $C_{t+1} / C_{t}$ is (gross) growth in real per capita personal consumption during period $t+1$. Comparing equation (4) with equation (6), stochastic discount factor, $m_{t+1}$, is equal to $\beta\left(C_{t+1} / C_{t}\right)^{\alpha}$. We can estimate expected value of $R_{t+1}$ given the expected value of real per capita consumption growth and estimated parameters. This expected value of real payoff gives fundamental value of S\&P500.

On the other side, the asset pricing model derived in (De Long et al 1990a) uses overlapping generations model framework with constant absolute risk aversion (CARA). There are two types of investors, fundamentalists, known as sophisticated investors, and noise traders. Both types of investors choose their portfolios, comprising of risky and riskless assets, when young to maximize their belief-oriented expected utility. They invest whole of their exogenously determined wealth in the first period in two available assets, risky and riskless. 
Both the assets pay identical real dividend $r$. Riskless asset is inelastic in supply whereas risky asset holds a fixed supply normalized to one unit. The investors hold different beliefs of the expected price of risky asset in the next period. The representative sophisticated investor correctly perceives, in the current period, the distribution of next period returns of the risky asset. On the other side, the representative noise trader misperceives the expected price of the risky asset. This misperception is shown in the model by an independent and identically distributed normal random variable $\rho_{t}$. $\rho_{t}$ is normally distributed with mean $\rho^{*}$ and variance $\sigma_{\rho}^{2}$. It solves the model by maximizing the following expected utility given respective expected values of the price of risky asset in the next period and shares of two types of investors.

$$
E(U)=w^{*}-\gamma \sigma^{2}
$$

where $w^{*}$ is the expected wealth, $\sigma^{2}$ is the one period ahead variance of wealth, and $\gamma$ is the coefficient of absolute risk aversion. Maximizing the above function, with two agents, and equating them to the fixed supply of risky asset gives following pricing function:

$$
R_{t}=p_{t}=1+\left(\mu\left(\rho_{t}-\rho^{*}\right) /(1+r)\right)+\left(\mu \rho^{*} / r\right)-\left((2 \gamma) \mu^{2} \sigma_{\rho}^{2} / r(1+r)^{2}\right)
$$

where, $p_{t}$ or $R_{t}$ is real payoff on risky asset at time $t, \mu$ is share of noise traders in the market, $\rho_{t}$ indicates misperception of expected price of risky asset by noise traders at time $t, \rho^{*}$ shows mean misperception of expected price of risky asset by noise traders, $r$ is fixed real (risk free) rate of return, $\gamma$ is coefficient of absolute risk aversion, and $\sigma_{\rho}^{2}$ serves as variance of noise traders' misperception of the expected return per unit of risky asset. Mathematical manipulation of equation (8) gives following equation.

$$
p_{t}\left(1 /\left(1+\left(\mu\left(\rho_{t}-\rho^{*}\right) /(1+r)\right)+\left(\mu \rho^{*} / r\right)-\left((2 \gamma) \mu^{2} \sigma_{\rho}^{2} / r(1+r)^{2}\right)\right)\right)-1=0
$$

Comparing equation (9) with equation (4) the stochastic discount factor, $m_{t+1}$, is $1 /\left(1+\left(\mu\left(\rho_{t-\rho^{*}}\right) /(1+r)\right)+\left(\mu \rho^{*} / r\right)-\left((2 \gamma) \mu^{2} \sigma_{\rho}^{2} / r(1+r)^{2}\right)\right)$. Equation (9) suggests that if there is no noise trader $(\mu=0)$, price (real payoff) will be equal to one, the fundamental value of risky asset. Second term, $\mu\left(\rho_{t}-\rho^{*}\right) /(1+r)$, shows variation in price due to variation of noise traders' misperception at time $t$. Third term, $\mu \rho^{*} / r$, shows variation of price due to the existence of nonzero average misperception of noise traders. This price pressure moves the price higher than fundamental value if $\rho^{*}$ is positive and vice versa. Fourth term, $(2 \gamma) \mu^{2} \sigma_{\rho}^{2} / r(1+r)^{2}$, indicates that sophisticated investors would require higher return to get themselves compensated against the risk that the noise traders would go against them and price of risky asset would miss their expectations. Last three terms signify that even in the absence of fundamental risk, price may deviate from fundamental value because of the presence of noise traders.

There exists a fundamental difference between the two models discussed above. Consumption based asset pricing model is developed on CRRA utility function and the asset pricing model with noise traders on CARA with mean variance framework. To have a precise estimation of the fundamental value, consistent with the CARA based mean variance framework, following theorem is 
M. Ahmed

used. It describes relationship between mean variance frontier portfolio payoff and the stochastic discount factor $\beta\left(C_{t+1} / C_{t}\right)^{\alpha}$ (Cochrane 2009).

Theorem: There exists a discount factor of the form $m=a+b R^{m v}$ if and only if $R^{m v}$ is on the mean-variance frontier, and $R^{m v}$ is not the risk-free rate. Where stochastic discount factor $m_{t+1}$ is equal to $\beta *\left(C_{t+1} / C_{t}\right)^{\alpha}, R^{m v}$ is payoff on mean-variance frontier. Considering this relationship fundamental value of mean-variance payoff can be estimated. If there comes any statistically significant value of $\mu$ in estimation of the HAM, there will exist heterogeneous investors, including fundamental and noise traders, and its value will represent proportion of noise trading in the market. In this case, the presence of noise traders will impact asset prices and the rational arbitragers would require additional return against the noise traders' risk.

\section{Methodology}

To estimate the two models, S\&P500 index monthly data is taken from January 1981 to June 2018, similarly real per capita personal consumption (non-durable) data and monthly population is taken for the same period and frequency. Inflation is computed using the difference between growth rates of nominal and real per capita consumption. It computes real payoff on S\&P500 index by discounting nominal payoff with inflation rate. All the data series are taken from FRED (Federal Reserve Economic Data $)^{1}$.

To estimate both the models Generalized Methods of Moments (GMM) is used as developed in the Hansen and Singleton (1982). Estimation of parameters through GMM method requires orthogonality conditions to be defined based on the theoretical economic model. These orthogonality conditions are used to form a criterion function which is then minimized with the choices in parameter values. This estimation ensures asymptotic normality. Further the criterion function also provides a base for testing the overidentification conditions. It requires total number of parameters to be at least as large as the number of orthogonality conditions. The orthogonality conditions need to satisfy some other conditions like the information of instrumental variables should be available at the time $t$. The general moment condition for discrete time models is as follows:

$$
E_{t}\left(v_{t+i}\right)=E_{t}\left[h\left(x_{t+i}, b_{0}\right)\right]=0
$$

where $E_{t}$ represents the expectations taken at time $t, x_{t+i}$ is the k-dimensional vector of variables, $b_{0}$ is the l-dimensional vector of unknown parameters. This leaves $E_{t} v_{t+i}$ as m-dimensional vector, where $m=k+l$. Here the instrumental variables should be observed by traders or agents. There is n-dimensional vector of instrumental variables. With these instrumental variables the criterion function transforms as follows:

$$
E_{t}\left[u_{t+i}\right]=E_{t}\left[h\left(x_{t+i}, b_{0}\right) \otimes z_{t}\right]=E_{t}\left[h\left(x_{t+i}, z_{t}, b_{0}\right)\right]=0
$$

where $z_{t}$ is the n-dimensional vector of instrumental variables. $z_{t} \subseteq F_{t}$ (information structure). Here, the number of equations reach to p-dimensional vector (where

1 Except for S\&P-500 index data which is partly taken from Yahoo Finance 
$p=m * n) . \otimes$ shows the Kronecker product. Estimation of $b_{0}$ requires $\mathrm{p}$ to be at least as large as 1 , number of unknown parameters. Further $v_{t+i}$ and $u_{t+i}$ should have finite second moments. Following is the method to obtain the function given the available information set:

$$
g_{T}(b)=1 / T \sum_{t=1}^{T} u_{t+i}=1 / T \sum_{t=1}^{T} h\left(x_{t+i}, z_{t}, b\right)
$$

It is evaluated at $b=b_{0}$. It selects value of $b$ from a parameter space which minimizes the following function:

$$
J_{T}(b)=g_{T}(b)^{\prime} W_{T} g_{T}(b)
$$

where $W_{T}$ is the pxp weighting matrix, which is positive definite and symmetric. To get a consistent estimator, there is a need to estimate the following matrix:

$$
W_{T}=1 / T \sum_{t=1}^{T} h\left(x_{t+i}, z_{t}, b\right) h\left(x_{t+i}, z_{t}, b\right)^{\prime}
$$

Initial values of $b_{0}$ can be estimated by using identity matrix of pxp order. The two-step estimation method gives more consistent estimators when the sample size is larger however in case of small sample, iterative method gives better and more consistent estimators. Estimation through GMM requires no joint distribution to be assumed but the instrumental variables should be predetermined. Equation (15) establishes the validity of the estimated models through the test of overidentifying restrictions.

$$
P=T J_{T}(b)
$$

$\mathrm{T}$ is the sample size used for estimation. J-statistics is assumed to follow Chisquare distribution with (pm-l) degrees of freedom. Acceptance of the nullhypothesis of J-statistics satisfies overidentifying restriction and its rejection reflects misspecification of model. Using this methodology, it estimates consumption based asset pricing model and the asset pricing model with noise traders' risk in this paper. Following are the moment conditions, for both the models. The estimated consumption-based pricing model has following moment condition with four lags of $R_{t+1}$ and $\left.\left(C_{t+1}\right) / C_{t}\right)$ as instruments.

$$
\left.\left.f\left(R_{t+1}, b_{0}\right)=\beta R_{(} t+1\right)\left(C_{t+1}\right) / C_{t}\right)^{\alpha}-1=0
$$

here $i=1, b_{0}$ are the set of parameters $\alpha$ and $\beta$. The asset pricing model with noise trader risk transforms into moment condition at time $t+1$ as follows:

$$
\begin{array}{r}
f\left(p_{t+1}, b_{0}\right)=f\left(R_{t+1}, b_{0}\right)=R_{t+1}\left(1 /\left(1+\mu\left(\rho_{t+1}-\rho^{*}\right) /(1+r)+\left(\mu \rho^{*}\right) / r-\right.\right. \\
\left.\left.\left((2 \gamma) \mu^{2} \sigma_{\rho}^{2}\right) /\left(r(1+r)^{2}\right)\right)\right)-1=0
\end{array}
$$

It takes four lags of $\rho_{t+1}$ and $R_{t+1}$ into account as instruments to estimate with multiple values of $\gamma$. Estimation of both the models through GMM brings consistency and provides room for unbiased comparison of the two models.

Business Review: (2019) 14(2):1-12 


\section{Ahmed}

GMM is recognized as one of the most widely applicable estimation techniques for asset pricing models. Cochrane (2009) and Hall (2005) provide substantial details on account of this technique. Hall (2005) also enlists major studies from several fields where GMM is used including a detailed list of studies on equity pricing.

To estimate the asset pricing model with noise traders' risk, it requires fundamental value (real payoff) derived from the mean-variance return. This mean-variance return / payoff is estimated using the theorem as described in the previous section in the following manner.

$$
m_{t+1}=a+b R_{t+1}^{m v}
$$

It implies

$$
R_{t+1}^{m v}=\left(m_{t+1}-a\right) / b
$$

Applying conditional expectation gives,

$$
E\left(R_{t+1}^{m v} \mid m_{t+1}\right)=\left(m_{t+1}-a\right) / b
$$

Difference of estimated mean-variance payoff from actual real payoff is taken as noise traders' misperception $\left(\rho_{t}\right)$.

\section{Estimation results}

Table 1 shows the estimation results of the representative agent model using two-step GMM with four lags of real per capita personal consumption growth and four lags of real payoff on S\&P500 index as instrumental variables. Estimated beta or the discount factor is 0.9948 , which is less than one. In line with the theory, it suggests that investors require compensation to forego current consumption for the future consumption. Value of the parameter $\alpha$ is -0.9215 , which shows that $\gamma$ (coefficient of risk aversion) is equal to 0.0785 , which is less than one. It indicates that investors are risk averse, on average. These parameters are used to find the fundamental value which gives the noise traders' misperception over time. This is shown by $\rho_{t}$, in the HAM, estimated in this paper. It estimates

Table 1: Estimation results of consumption-based asset pricing model

\begin{tabular}{cccccc}
\hline$\alpha$ & $\mathrm{S} . \mathrm{E}(\alpha)$ & $\beta$ & $\mathrm{S} . \mathrm{E}(\beta)$ & $\chi^{2}$ & Prob \\
\hline$-0.9215^{* *}$ & 0.0453 & $0.9948^{* * *}$ & 0.0001 & 1.9311 & 0.9636 \\
\hline$* * *$ Significant at $1 \%$ ** Significant & at $5 \%$ & &
\end{tabular}

the asset pricing model with noise traders' risk through iterative-GMM. Four lags of real payoff on S\&P 500 index and four lags of misperception of noise traders $\rho_{t}$ are used as instrumental variables. $R_{t}$ is the monthly real payoff on S\&P500 index. $r$ is the monthly real rate of return computed using one-year treasury rate. Its average value is used as an estimate of $r$ as the constant value of real risk-free rate. Fundamental value is the forecasted value of mean-variance 
Estimating proportion of noise traders...

Table 2: Estimation of equation (18) - Relationship between stochastic discount factor and mean-variance payoff

\begin{tabular}{cccccc}
\hline $\mathrm{a}$ & $\mathrm{S} . \mathrm{E}(\mathrm{a})$ & $\mathrm{b}$ & $\mathrm{S} . \mathrm{E}(\mathrm{b})$ & $\chi^{2}$ & Prob \\
\hline $1.0742^{* * *}$ & 0.0030 & $-0.0799^{* * *}$ & 0.0030 & 1.7070 & 0.9743 \\
\hline *** Significant at $1 \%$ & & & &
\end{tabular}

Table 3: Estimation results of asset pricing model with noise traders' risk

\begin{tabular}{|c|c|c|c|c|c|}
\hline$\gamma$ & $\mu$ & S.E $(\mu)$ & $\chi^{2}$ & Prob. & $\mathrm{SD}\left(\epsilon_{t}\right)$ \\
\hline-1.00 & $0.0278^{* * *}$ & 0.0009 & 1.5845 & 0.9912 & 0.0418 \\
\hline-0.95 & $0.0283^{* * *}$ & 0.0009 & 1.5840 & 0.9912 & 0.0417 \\
\hline-0.90 & $0.0288^{* * * *}$ & 0.0009 & 1.5834 & 0.9912 & 0.0417 \\
\hline-0.85 & $0.0294^{* * *}$ & 0.0010 & 1.5828 & 0.9912 & 0.0417 \\
\hline-0.80 & $0.0300^{* * *}$ & 0.0010 & 1.5822 & 0.9913 & 0.0417 \\
\hline-0.75 & $0.0306^{* * *}$ & 0.0010 & 1.5816 & 0.9913 & 0.0417 \\
\hline-0.70 & $0.0313^{* * *}$ & 0.0010 & 1.5809 & 0.9913 & 0.0417 \\
\hline-0.65 & $0.0320^{* * *}$ & 0.0011 & 1.5801 & 0.9913 & 0.0416 \\
\hline-0.60 & $0.0328^{* * *}$ & 0.0011 & 1.5793 & 0.9913 & 0.0416 \\
\hline-0.55 & $0.0336^{* * *}$ & 0.0011 & 1.5784 & 0.9913 & 0.0416 \\
\hline-0.50 & $0.0346^{* * *}$ & 0.0012 & 1.5775 & 0.9913 & 0.0416 \\
\hline-0.45 & $0.0356^{* * *}$ & 0.0012 & 1.5764 & 0.9914 & 0.0415 \\
\hline-0.40 & $0.0368^{* * *}$ & 0.0013 & 1.5753 & 0.9914 & 0.0415 \\
\hline-0.35 & $0.0381^{* * *}$ & 0.0014 & 1.5740 & 0.9914 & 0.0415 \\
\hline-0.30 & $0.0395 * * *$ & 0.0014 & 1.5726 & 0.9914 & 0.0414 \\
\hline-0.25 & $0.0412^{* * *}$ & 0.0015 & 1.5710 & 0.9915 & 0.0414 \\
\hline-0.20 & $0.0432 * * *$ & 0.0016 & 1.5691 & 0.9915 & 0.0413 \\
\hline-0.15 & $0.0456^{* * *}$ & 0.0018 & 1.5670 & 0.9915 & 0.0412 \\
\hline-0.10 & $0.0485^{* * *}$ & 0.0020 & 1.5645 & 0.9916 & 0.0412 \\
\hline-0.05 & $0.0523 * * *$ & 0.0022 & 1.5614 & 0.9916 & 0.0411 \\
\hline 0.00 & $0.0575^{* * *}$ & 0.0027 & 1.5574 & 0.9917 & 0.0409 \\
\hline 0.05 & $0.0657^{* * *}$ & 0.0035 & 1.5522 & 0.9918 & 0.0407 \\
\hline 0.10 & $0.0844^{* * *}$ & 0.0067 & 1.5446 & 0.9919 & 0.0403 \\
\hline 0.15 & $0.0930 * * *$ & 0.0166 & 1.5961 & 0.9910 & 0.0401 \\
\hline 0.20 & $0.0740^{* * *}$ & 0.0161 & 1.6583 & 0.9898 & 0.0405 \\
\hline 0.25 & $0.0613^{* * *}$ & 0.0158 & 1.6826 & 0.9892 & 0.0408 \\
\hline 0.30 & $0.0523 * * *$ & 0.0156 & 1.6943 & 0.9890 & 0.0411 \\
\hline 0.35 & $0.0455^{* * *}$ & 0.0154 & 1.7011 & 0.9888 & 0.0412 \\
\hline 0.40 & $0.0403^{* * *}$ & 0.0152 & 1.7055 & 0.9887 & 0.0414 \\
\hline 0.45 & $0.0362^{* *}$ & 0.0151 & 1.7084 & 0.9887 & 0.0415 \\
\hline 0.50 & $0.0328^{* *}$ & 0.0151 & 1.7106 & 0.9886 & 0.0416 \\
\hline 0.55 & $0.0300 * *$ & 0.0150 & 1.7122 & 0.9886 & 0.0417 \\
\hline 0.60 & $0.0276^{*}$ & 0.0149 & 1.7134 & 0.9886 & 0.0418 \\
\hline 0.65 & $0.0256^{*}$ & 0.0149 & 1.7145 & 0.9885 & 0.0418 \\
\hline 0.70 & 0.0239 & 0.0148 & 1.7152 & 0.9885 & 0.0419 \\
\hline 0.75 & 0.0223 & 0.0148 & 1.7159 & 0.9885 & 0.0419 \\
\hline 0.80 & 0.0210 & 0.0148 & 1.7165 & 0.9885 & 0.0420 \\
\hline 0.85 & 0.0198 & 0.0147 & 1.7170 & 0.9885 & 0.0420 \\
\hline 0.90 & 0.0188 & 0.0147 & 1.7174 & 0.9885 & 0.0420 \\
\hline 0.95 & 0.0178 & 0.0147 & 1.7177 & 0.9885 & 0.0421 \\
\hline 1.00 & 0.0169 & 0.0147 & 1.7181 & 0.9885 & 0.0421 \\
\hline
\end{tabular}

$* * *$ Significant at $1 \% * *$ Significant at $5 \% *$ Significant at $10 \%$

Business Review: (2019) 14(2):1-12 
M. Ahmed

Table 4: Summary of residuals of estimated models

\begin{tabular}{lrrrr}
\hline Model & Mean & Std dev & Min val & Max val \\
\hline Consumption-based asset pricing model & 0.000 & 0.042 & -0.126 & 0.224 \\
Asset pricing model with noise traders' risk & 0.000 & 0.040 & -0.100 & 0.206 \\
\hline
\end{tabular}

return $E\left(R_{t+1}^{m v} \mid m_{t+1}\right)$ estimated from equation (20). Stochastic discount factor, $m$, is computed using the estimated parameters of consumption-based asset pricing model and growth on real per capita personal consumption. $R^{m v}$ is real payoff on S\&P 500 index. S\&P 500 index as representative market portfolio is taken as a well-diversified and mean-variance efficient portfolio. In the estimation of above model through two-step GMM, four lags of real payoff on S\&P 500 index and four lags of stochastic discount factor give estimated parameters as shown in table 2 .

Both the parameters are statistically significant. Parameter $a$ shows mean value of stochastic discount factor when mean-variance payoff is zero. It shows that, if the payoff is one or the return is zero, stochastic discount factor will be 0.9943. Parameter $b$ shows that mean-variance payoff negatively affects stochastic discount factor. $1 \%$ increase in real payoff decreases stochastic discount factor by $0.08 \%$. Higher payoff / return will be associated with lower value of stochastic discount factor or higher discount rate. It derives conditional expectation of $R^{m v}$, which is the fundamental value or expected real payoff using equation (19).

$\rho^{*}$ and $\sigma_{\rho}^{2}$ are computed mean and variance of the noise traders' misperception. Estimated parameter in the model is $\mu$, which reflects proportion of the noise traders in the market. It estimates the parameter through GMM with multiple values of $\gamma$, coefficient of absolute risk aversion, starting from -1 to 1 with an interval of $0.05^{2}$. Table 3 gives estimation results of the asset pricing model with noise traders' risk.

The results indicate the presence of noise traders in the market. Value of coefficient of absolute risk aversion, $\gamma$, equal to 0.15 gives least RMSE (root mean squared error) and shows that 9.3\% $(\mu)$ trading in S\&P500 is attributed to the noise traders, on average. Inclusion of heterogeneous traders in the asset pricing model gives lower RMSE as compared to consumption-based asset pricing model which reflects improvement in the model. Further positive value of $\mu$ suggests that the noise traders exaggerate price expectations by unintentionally following fundamental value. Table 4 compares the summary statistics of the two models.

\section{Conclusion}

This paper concludes that noise traders are present in the S\&P500 and $9.3 \%$ of trading has been attributed to them in the selected period. Investors are risk averse, on average, as shown by the value of coefficient of absolute risk

\footnotetext{
$2 \gamma$ could not be estimated directly through GMM because it does not support calculation of numerical derivatives
} 
aversion, even in the presence of noise traders. Positive share of noise traders reflects that, on average, they exaggerate the expected price in comparison to the rational arbitragers. They cause to amplify the magnitude of change in price by giving positive feedback to the fundamental value. Incorporating the noise traders beliefs in the market makes the model comparatively efficient. These results are consistent with the previously estimated HAMs for S\&P500, however, unlike previously estimated HAMs, it estimates fundamental value using the basic representative agent asset pricing model, which gives true comparison of HAM and RAM.

Estimation results of standard representative agent asset pricing model suggest that the investors are rational as value of $\alpha$ is negative leaving $\gamma$, the coefficient of relative risk aversion, less than one. The discount factor is less than one which shows that investors give more weight to one dollar of consumption today as compared to the one-dollar consumption in future. Estimation of the HAM provides evidence, statistically, that there exist noise traders having distinctive beliefs as compared to rational arbitragers or fundamentalists. Their presence makes a significant impact on asset pricing through noise trader's risk.

There are some interesting implications of the positive value of $\mu$. It supports the positive feedback behavior showing that noise traders unintentionally follow fundamental value. However, it leaves a question open that whether there are only positive feedback traders / followers or there are some contrarians in the market as well? This requires further investigation and extension in the heterogeneous agent model.

\section{References}

Anderson EW, Ghysels E, Juergens JL (2005) Do heterogeneous beliefs matter for asset pricing? The Review of Financial Studies 18(3):875-924

Barberis N, Shleifer A, Vishny R (1998) A model of investor sentiment. Journal of financial economics 49(3):307-343

Barberis N, Greenwood R, Jin L, Shleifer A (2015) X-capm: An extrapolative capital asset pricing model. Journal of financial economics 115(1):1-24

Black F (1986) Journal of finance, volume 41, issue 3, papers and proceedings of the fortyfourth annual meeting of the america finance association, new york, new york, december 20-30, 1985 (jul., 1986), 529-543. The Journal of Finance 41(3)

Boswijk HP, Hommes CH, Manzan S (2007) Behavioral heterogeneity in stock prices. Journal of Economic dynamics and control 31(6):1938-1970

Chiarella C, He XZ, Huang W, Zheng H (2012) Estimating behavioural heterogeneity under regime switching. Journal of Economic Behavior \& Organization 83(3):446-460

Chiarella C, He XZ, Zwinkels RC (2014) Heterogeneous expectations in asset pricing: Empirical evidence from the s\&p500. Journal of Economic Behavior \& Organization 105:1-16

Cochrane JH (2009) Asset pricing: Revised edition. Princeton university press

De Long JB, Shleifer A, Summers LH, Waldmann RJ (1990a) Noise trader risk in financial markets. Journal of political Economy 98(4):703-738

De Long JB, Shleifer A, Summers LH, Waldmann RJ (1990b) Positive feedback investment strategies and destabilizing rational speculation. the Journal of Finance 45(2):379-395

Grossman SJ, Stiglitz JE (1980) On the impossibility of informationally efficient markets. The American economic review 70(3):393-408

Hall AR (2005) Generalized method of moments. Oxford university press

Hansen LP, Singleton KJ (1982) Generalized instrumental variables estimation of nonlinear rational expectations models. Econometrica: Journal of the Econometric Society pp 12691286

Business Review: (2019) 14(2):1-12 
M. Ahmed

Hommes C, et al (2017) Booms, busts and behavioural heterogeneity in stock prices. Journal of Economic Dynamics and Control 80:101-124

Hong H, Stein JC (1999) A unified theory of underreaction, momentum trading, and overreaction in asset markets. The Journal of finance 54(6):2143-2184

Kyle AS (1985) Continuous auctions and insider trading. Econometrica: Journal of the Econometric Society pp 1315-1335

Lof M (2014) Rational speculators, contrarians, and excess volatility. Management Science 61(8):1889-1901

Lucas Jr RE (1978) Asset prices in an exchange economy. Econometrica: Journal of the Econometric Society pp 1429-1445

Markowitz H (1952) Portfolio selection. The journal of finance 7(1):77-91

Milgrom P, Stokey N (1982) Information, trade and common knowledge. Journal of economic theory $26(1): 17-27$

Russell T, Thaler R (1985) The relevance of quasi rationality in competitive markets. The American Economic Review 75(5):1071-1082

Simon HA (1997) Models of bounded rationality: Empirically grounded economic reason, vol 3. MIT press

Ter Ellen S, Verschoor WF (2018) Heterogeneous beliefs and asset price dynamics: a survey of recent evidence. In: Uncertainty, Expectations and Asset Price Dynamics, Springer, pp 53-79

Thaler RH, Shefrin HM (1981) An economic theory of self-control. Journal of political Economy 89(2):392-406

Tversky A, Kahneman D (1974) Judgment under uncertainty: Heuristics and biases. science 185(4157):1124-1131

Tversky A, Kahneman D (1979) Prospect theory: An analysis of decision under risk. Econometrica $47(2): 263-291$

Von Neumann J, Morgenstern O (1953) Theory of Games and Economic Behavior: 3d ed. Princeton university press

Zeeman EC (1974) On the unstable behaviour of stock exchanges. Journal of mathematical economics 1(1):39-49 